\title{
TO EVALUATE THE MARGINAL FIT OF METAL COPINGS FABRICATED BY CONVENTIONAL CASTING PROCEDURE AND DIRECT METAL LASER SINTERING TECHNOLOGY - AN IN VITRO STUDY
}

\author{
Monica Sharma ${ }^{1}$, Ajay Bansal ${ }^{2}$, Sunny Panthi ${ }^{3}$, Shefali S Malik ${ }^{4}$, Atulya Sharma ${ }^{5}$ \\ 'Senior Lecturer, Dept. of Prosthodontics, Bhojia Dental College and Hospital, Himachal Pradesh, India \\ ${ }^{2}$ Reader, Dept. of Prosthodontics, Bhojia Dental College and Hospital, Himachal Pradesh,India \\ ${ }^{3}$ Senior Lecturer, Dept. of Prosthodontics, Bhojia Dental College and Hospital, Himachal Pradesh, India \\ ${ }^{4}$ Senior Lecturer, Dept. of Prosthodontics, Bhojia Dental College and Hospital, Himachal Pradesh, India \\ ${ }^{5}$ Senior Lecturer, Dept. of Prosthodontics, Bhojia Dental College and Hospital, Himachal Pradesh, India
}

\begin{abstract}
'Senior Lecturer
ABSTRACT

Purpose: The purpose of this in vitro study was to evaluate marginal fit of cobalt- chromium (Co-Cr) copings fabricated by direct metal laser sintering system (DMLS) and conventional lost-wax technique (LW). Materials and method: Forty tooth preparations were carried out over extracted mandibular molars. They were divided into two groups A and B of 20 each. For group A Co-Cr copings were fabricated by direct metal laser sintering (DMLS) and for group B by lost wax technique (LW). Glass -ionomer cement (GIC) was used to tack the copings over their preparations. Marginal fit was then evaluated directly under the stereomicroscope. Results: The mean marginal gap of group A was $27.9 \pm 2.4 \mu \mathrm{m}$ and group B was $40.4 \mu \mathrm{m}$. Statistical analysis using $\mathrm{t}$ - test showed highly significant difference $(\mathrm{P}>.05)$ between the marginal mean of the DMLS (group A) compared to LW (group B). Conclusion: The DMLS copings demonstrated superior marginal fit compared to that of conventional Co-Cr casted copings.
\end{abstract}

Keywords: Cobalt Chromium, Direct metal laser sintering, Porcelain fused metal crowns

\section{INTRODUCTION}

Metal fused to ceramic prosthesis is still the most widely used restoration material for fabricating complete coverage crowns and partial fixed dental prostheses. ${ }^{1}$ A porcelain fused to metal prosthesis is made by sintering layers of porcelain over metal coping. An essential factor for the success of a metal-ceramic fixed dental prosthesis is marginal fit of the metal coping. ${ }^{2,3}$ Excessive marginal discrepancy for crowns increases cement dissolution and microleakage and can cause inflammation of the vital pulp. ${ }^{4}$ Poor

Corresponding Author: Monica Sharma

E-mail:

drmonica.sharma@yahoo.com Received: $25^{\text {th }}$ December 2016

Accepted: $3^{\text {rd }}$ April 2017

Online: $20^{\text {th }}$ May 2017 marginal adaptation of crowns increases plaque retention, ${ }^{5,6}$ changes the composition of the subgingival microflora, ${ }^{7}$ and can result in the onset of periodontal disease.
Casting of metal copings has traditionally been carried out by lost wax (LW) technique given by Taggart in 1907. Initially noble alloys were used for fabricating metal copings because of their ease of use and biocompatibility. ${ }^{8}$ However with time manufacturers shifted to less costly alternatives like the base metal alloys. Casting of all base metal alloys is more technique sensitive compared to casting of noble alloys because of their high melting range and oxidation of base metal alloys during casting. ${ }^{8-11}$ In addition, due to their high hardness, grinding of base metals especially Co-Cr alloys, to finish castings is comparatively time consuming for dental laboratories. ${ }^{12}$ Such limitations of casting procedures has led to introduction 
of direct metal laser-sintering (DMLS) system to dentistry.

The newly developed direct metal lasersintering (DMLS) system is a rapid prototyping method for fabricating metal products directly from computer-aided design (CAD) data. Automated fabrication is accomplished layer-by-layer by selectively fusing together metal powders with the help of a laser beam. Advantages of the DMLS system include ease of fabrication, use of fully automated system, and comparatively shorter working time. ${ }^{3}$ Also, metal copings fabricated with DMLS have been reported to have satisfactory mechanical and chemical properties. $^{13-16}$

While an essential condition for a successful dental prosthesis is good marginal fit, there is little data on the marginal fit of fixed dental prostheses (FDPs) fabricated by the DMLS system. ${ }^{3,8,17-21}$

The purpose of this in vitro study was to evaluate and compare the marginal fit of $\mathrm{Co}-\mathrm{Cr}$ copings, fabricated by direct metal laser-sintering technology and conventional lost wax technique. The hypothesis for the study was that marginal fit of copings fabricated with both the techniques i.e. DMLS and lost wax techinque would be same.

\section{MATERIALAND METHOD}

Forty caries-free natural mandibular molars, extracted for reasons other than the study, were selected. They were cleaned and stored in $0.1 \%$ thymol solution (Amrit chemicals Ltd,India) at room temperature throughout the course of the study, to prevent them from drying and becoming brittle. Each tooth was mounted over self-cure acrylic resin mount (Self cure, DPI, India).

\section{Tooth preparation and Die Fabrication}

The tooth preparation of all the fourty specimens was done following standard preparation protocol, ${ }^{22}$ using a high-speed angled handpiece and diamond rotary cutting instruments under water cooling. A $1.2 \mathrm{~mm}$ wide, smooth, continuous, shoulder finish line was prepared, $2 \mathrm{~mm}$ above cemento-enamel junction and an occlusal reduction of $1.5 \mathrm{~mm}$ was done (Figure 1). The convergence angle of the preparation

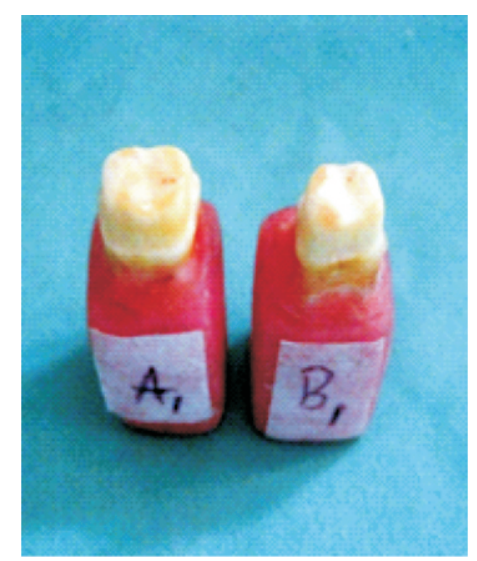

Figure 1: Prepared teeth

corresponded to the convergence angle of diamond rotary cutting instrument. New diamond bur was used for every tooth preparation. To control the amount of tooth reduction while doing tooth preparation silicone putty index (Putty, 3M EPSE, Germany) was used and a periodontal probe was used to gauge the tooth reduction. Impressions were made for each sample in custom tray fabricated with self cure resin(DPI) using medium-body polyvinyl siloxane impression material (Aquasil Monophase, Dentsply, USA). Dies were poured in type IV die-stone (Kalrock, Kalabhai, India) (Figure 2). Specimens were then divided into two

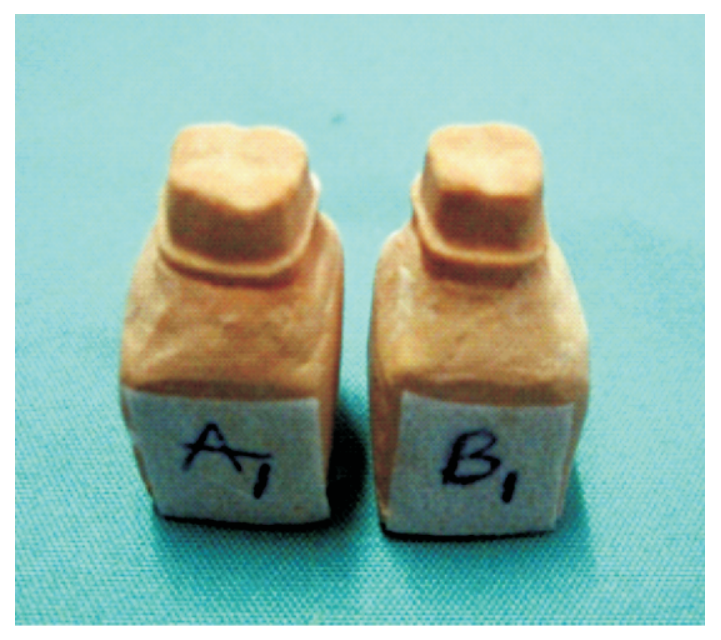

Figure 2: Stone Dies 
groups (A\&B) of twenty sample each over which copings with direct metal laser sintering and conventional casting were fabricated.

\section{Fabrication of copings}

GROUP A consisted of copings fabricated by DMLS technology. All 20 dies (A1-A20) were first scanned by an optical scanner (Lava Scan ST scanner, 3M ESPE Lava, Germany). The scanner software program converted the data points into 3D CAD data to form a digitilised die. In the CAD process (Figure 3), coping

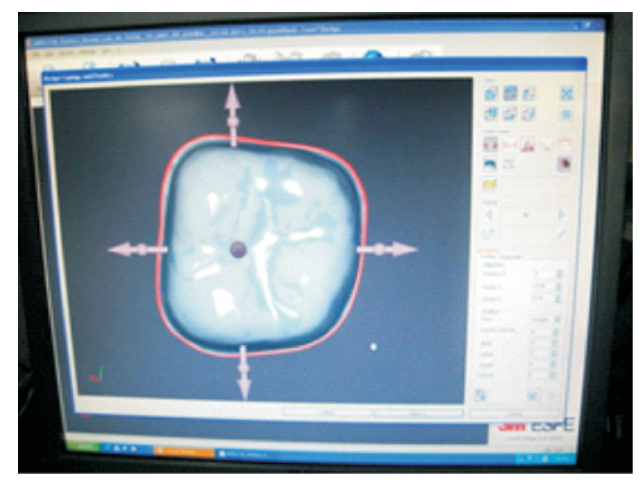

Figure 3: Formation of wax pattern using $\mathrm{CAD}$ on digitalized die of group $\mathrm{A}$

thickness was set at $0.5 \mathrm{~mm}$, cement thickness $30 \mu \mathrm{m}$, starting at $0.5 \mathrm{~mm}$ above the margin. The 3D CAD data was then sent to a fabrication center where, $20 \mathrm{Co}-\mathrm{Cr}$ alloy (SP2 powder - Co: 61.8-65.8, Cr: 23.7-25.7, W: 4.9-5.9, Mo: 4.6-5.6, Si: 0.8-1.2, Fe: $\max 0.5$, Mn: $\max$ 0.1 ) copings were completed using the DMLS equipment (EOSINT M270). Each coping was subsequently sandblasted with $125 \mu \mathrm{m}$ aluminum oxide at a pressure of 3 bar.

GROUP B consisted of conventional CobaltChromium (Co: 64, Cr:28, W: 5.3, Mo: 5.1 Si: $\max 1.0$, Fe: $\max 1.0$, Ce: $\max 1.0$; Wirobond $\mathrm{C}+$; Bego Dental) copings fabricated by lost wax technique. All 20 dies (B1-B20) were treated with a die hardener (Han Dae Chemical Co.LTD, Korea) applied in 2 steps without creating a visible surface layer. After drying, 3 coats of die spacer (Han Dae Chemical Co.LTD, Korea) were applied within $0.5 \mathrm{~mm}$ of the margin. The wax pattern was fabricated with a dip-wax technique (Blue inlay wax, Bego, Germany) and a subsequent readaptation of the margin with the sealing wax. Iwanson's wax thickness measuring gauge was used to confirm the thickness of each coping to be $0.5 \mathrm{~mm}$.

Each wax pattern was directly connected with a wax sprue (Bego, Germany) 3-mm in diameter and 6 $\mathrm{mm}$ in length to the base of the sprue former. Wax patterns were invested in a phosphate bonded investment (Bellasum, Bego, Germany) in metal casting rings lined with cellulose acetate ring liner, following the powder/liquid ratio as recommended by manufacturer. After a setting time of 60 minutes casting ring was kept in preheated furnace at $250^{\circ} \mathrm{C}$ for $30-60$ min and then heated up to final temperature of $900^{\circ} \mathrm{C}$ maintaining for $30-60 \mathrm{~min}$. The casting of Co-Cr alloy (Co: 64, Cr:28, W: 5.3, Mo: 5.1 Si: $\max 1.0$, Fe: $\max$ 1.0, Ce: max 1.0 ; Wirobond C+; Bego Dental) was carried out in induction casting machine. They were then bench cooled, divested and air-abraded with 50 $\mu \mathrm{m}$ aluminum oxide particles and separated from the sprues using a carborundum disc. Airborne particle abrasion was repeated externally and internally with $150-\mu \mathrm{m}$ aluminum oxide and at 3 -bar pressure.

\section{Marginal Fit Measurements}

The marginal fit was measured as the gap between the external edge of metal coping and the tooth preparation limit. Before measuring, each coping was luted on its respective tooth preparation (Figure 4) with

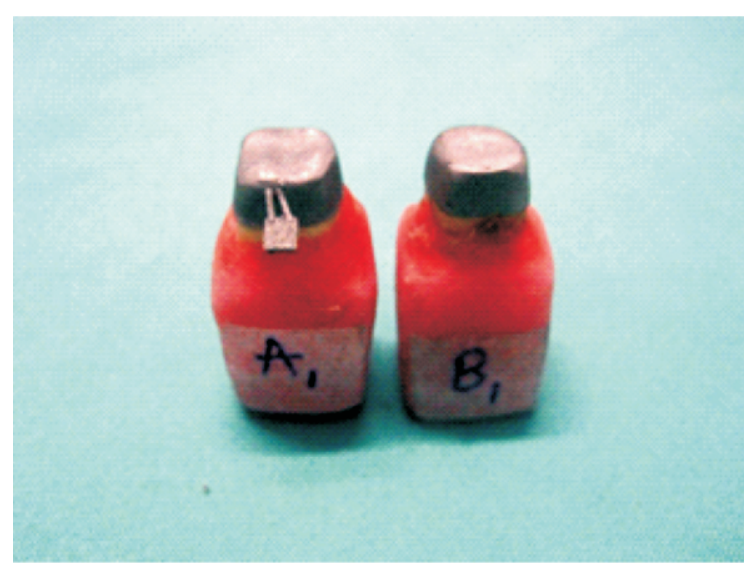

Figure 4: Copings luted over respective prepared tooth 
minimum amount of GIC (Glass Ionomer, GC Corporation, Japan) applied over the occlusal surface of the prepared tooth and secured with finger pressure for 3 min. ${ }^{23}$ The marginal gap was then examined using stereomicroscope $\times 40$ (Magnus, Olympus, Tokyo, Japan), and digital images were captured at each of the four surfaces mesial, distal, buccal and lingual. The flat base of the specimens along each surface prevented the specimens from moving and kept each surface perpendicular to the objective lens. Using image analysing software, five measurements were made at each of the four positions (Figure 5,6) for a total of 20 measurements per coping.

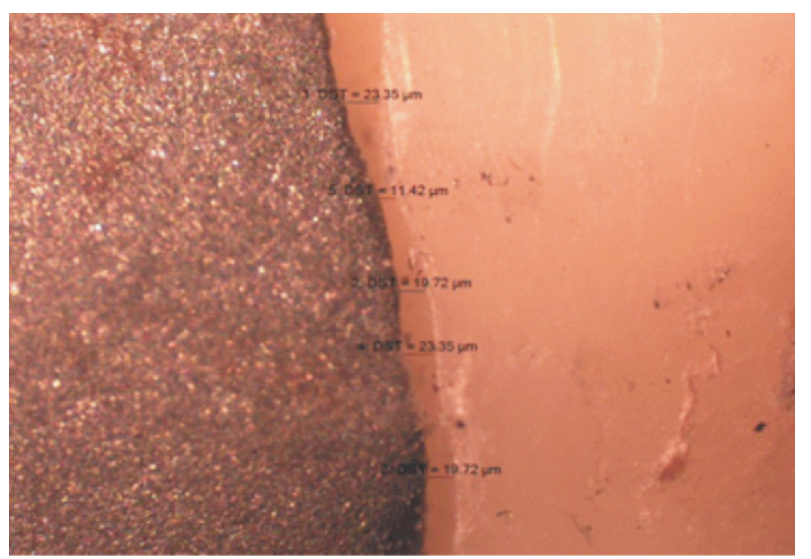

Figure 5: Marginal gap measurement for Group A using stereomicroscope

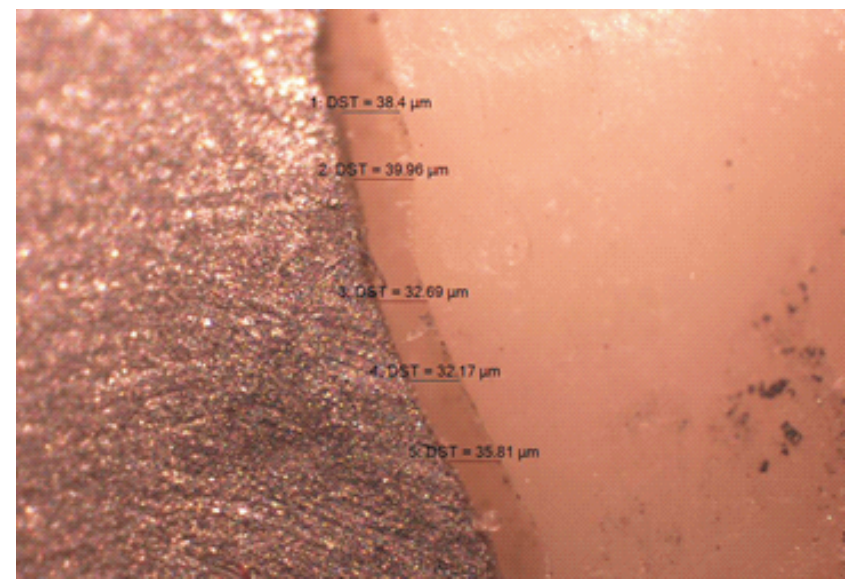

Figure 6: Marginal gap measurement for Group B using stereomicroscope

\section{RESULTS}

In total 800 marginal gap measurements were made for all the samples. The mean marginal gap values for each specimen of group A and group B are given in the table I and table II. The over all mean marginal gap of group A was $27.9 \pm 2.4 \mu \mathrm{m}$ and group B was $40.4 \pm 6 \mu \mathrm{m}$ (Table-III \& Graph-I). Statistical analysis using $\mathrm{t}$ - test showed (Table VI) highly significant difference between the overall mean marginal gap of group A compared to group B.

Table 1: Results for Group A

\begin{tabular}{|c|c|l|l|l|l|}
\hline GROUP A (DMLS) & $\begin{array}{c}\text { MEAN MARGINAL } \\
\text { GAP }\end{array}$ & $\begin{array}{l}\text { STANDARD } \\
\text { DEVIATION }\end{array}$ & MAXIMUM & MINIMUM & MEDIAN \\
\hline A1 & 25.3605 & 5.23 & 35.18 & 16.15 & 25.155 \\
\hline A2 & 29.732 & 6.906 & 39.96 & 19.42 & 31.09 \\
\hline A3 & 27.663 & 6.852 & 40.1 & 17.63 & 29.24 \\
\hline A4 & 24.602 & 4.637 & 34.71 & 15.67 & 23 \\
\hline A5 & 25.898 & 6.157 & 36.83 & 17.49 & 24.33 \\
\hline A6 & 26.814 & 5.838 & 35.99 & 17.11 & 27.64 \\
\hline A7 & 24.48 & 4.652 & 34.56 & 17.68 & 23.2 \\
\hline A8 & 24.62 & 4.2173 & 34.23 & 16.11 & 24.195 \\
\hline A10 & 29.551 & 6.141 & 38.96 & 19.56 & 30.83 \\
\hline A11 & 30.518 & 5.130 & 39.75 & 23.17 & 29.06 \\
\hline A12 & 27.17 & 4.37 & 37.89 & 20.87 & 26.17 \\
\hline A13 & 27.12 & 5.186 & 37.66 & 19.34 & 26.045 \\
\hline A14 & 27.53 & 4.460 & 37.84 & 21.56 & 27.085 \\
\hline A15 & 28.423 & 4.893 & 38.91 & 21.31 & 28.825 \\
\hline A16 & 30.861 & 5.239 & 39.88 & 21.34 & 31.995 \\
\hline A17 & 33.455 & 5.756 & 42.88 & 21.56 & 32.77 \\
\hline A19 & 28.997 & 5.758 & 38.91 & 18.91 & 29.155 \\
\hline A20 & 26.889 & 4.243 & 36.67 & 19.47 & 26.28 \\
\hline & 29.492 & 4.811 & 39.65 & 19.23 & 28.96 \\
\hline
\end{tabular}


Table II: Results for Group B

\begin{tabular}{|l|l|l|l|l|l|}
\hline GROUP B (LW) & \multicolumn{1}{|c|}{$\begin{array}{c}\text { MEAN MARGINAL } \\
\text { GAP }\end{array}$} & $\begin{array}{c}\text { STANDARD } \\
\text { DEVIATION }\end{array}$ & MAXIMUM & MINIMUM & MEDIAN \\
\hline B1 & 51.168 & 10.066 & 68.12 & 34.56 & 49.17 \\
\hline B2 & 53.818 & 12.25 & 78.56 & 32.87 & 53.215 \\
\hline B3 & 48.842 & 13.662 & 76.87 & 30.11 & 49.15 \\
\hline B4 & 42.165 & 17.334 & 77.85 & 19.78 & 38.42 \\
\hline B5 & 41.164 & 9.395 & 56.78 & 25.56 & 38.775 \\
\hline B6 & 34.128 & 5.457 & 39.76 & 22.34 & 35.83 \\
\hline B7 & 40.17 & 12.291 & 67.14 & 23.45 & 37.235 \\
\hline B8 & 45.155 & 9.231 & 67.45 & 32.11 & 42.99 \\
\hline B9 & 36.218 & 6.723 & 47.28 & 25.11 & 36.55 \\
\hline B10 & 42.84 & 8.105 & 58.34 & 30.17 & 40.31 \\
\hline B11 & 42.242 & 14.513 & 68.45 & 22.11 & 39.225 \\
\hline B12 & 35.257 & 5.999 & 49.43 & 23.11 & 36.455 \\
\hline B13 & 31.651 & 7.139 & 40.43 & 20.11 & 32.785 \\
\hline B14 & 32.892 & 5.095 & 43.99 & 21.99 & 32.32 \\
\hline B15 & 39.173 & 14.085 & 78.87 & 20.9 & 36.27 \\
\hline B16 & 36.273 & 6.952 & 48.97 & 23.11 & 37.715 \\
\hline B17 & 35.109 & 10.781 & 55.78 & 18.99 & 33.46 \\
\hline B18 & 38.678 & 7.308 & 48.56 & 24.76 & 38.17 \\
\hline B19 & 44.717 & 10.599 & 66.89 & 29.57 & 41.705 \\
\hline B20 & 37.756 & 10.068 & 67.45 & 25.77 & 37.56 \\
\hline
\end{tabular}

Table III: Overall mean marginal gap of Group A and Group B

\begin{tabular}{|l|l|c|c|c|c|}
\hline & GROUP & N & Mean & Std. Deviation & Std. Error Mean \\
\hline \multirow{2}{*}{$\begin{array}{l}\text { MARIGNAL } \\
\text { GAP }\end{array}$} & A & 20 & 27.93 & 2.36438 & 0.529 \\
\cline { 2 - 6 } & B & 20 & 40.47 & 6.04445 & 1.351 \\
\hline
\end{tabular}

Table IV: Comparison of mean marginal gap of Group A with Group B using independent t-test

\begin{tabular}{|c|c|c|c|c|c|c|}
\hline \multicolumn{7}{|c|}{ Independent Samples Test } \\
\hline \multicolumn{2}{|c|}{ t-test for Equality of Means } \\
\hline T & Df & Sig. (2-tailed) & Mean Difference & $\begin{array}{c}\text { Std. Error } \\
\text { Difference }\end{array}$ & \multicolumn{2}{|c|}{$\begin{array}{c}\text { 95\% Confidence Interval } \\
\text { of the Difference }\end{array}$} \\
\cline { 4 - 7 } & & & -12.54 & 1.451 & -15.53 & Lower \\
\hline-8.6 & 24.681 & $<.001^{* *}$ & & & -9.55 \\
\hline
\end{tabular}

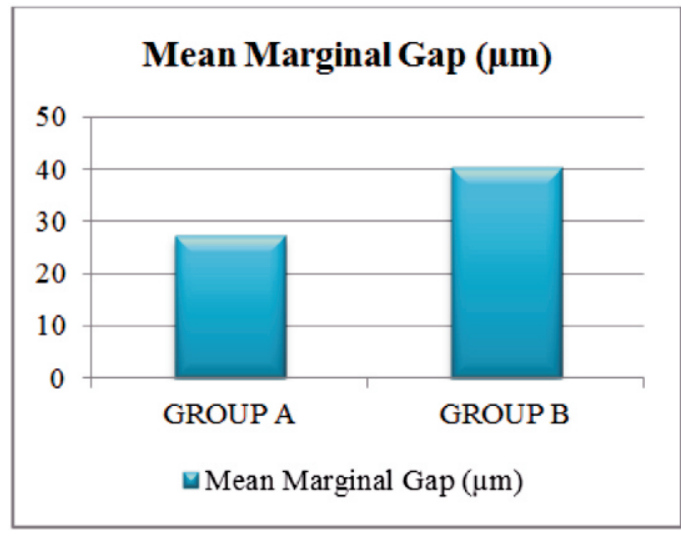

Graph I: Bar graph depicting mean marginal gap of Group A and Group B

\section{DISCUSSION}

Precise marginal fit is one of the most important criteria for the long term success of FPD's. ${ }^{8}$ The marginal discrepancy of metal copings may depend on several factors, such as, margin design configuration, type of alloy used, casting procedures, and subsequently cementation. Among these, casting is highly technique-sensitive, requiring qualified technicians, control of the wax pattern fabrication and investing procedure, and careful attention during the casting process. ${ }^{24}$ Many procedures are required to 
execute this process, which increases the possibility of mistakes affecting the accuracy and fit of copings made. To overcome these flaws, a new additive technique for forming the metal substructures has been introduced. Direct Metal Laser Sintering (DMLS) is a promising new technology that may avoid the distortions inherent to casting procedures. ${ }^{25}$ The CAD process of producing copings by DMLS technique using automated scanning process and powerful CAD software offers many advantages such as complete control over the framework and coping designing, margin placement and cement space maintenance. To date, very few studies have been published on the marginal fit of FPD's made by DMLS. Therefore, this study was carried out to assess the marginal fit of metal copings made by new DMLS technique compared with conventional casting procedure.

Co-Cr was used to fabricate the metal copings in the study, because currently they are used more commonly than Ni-Cr alloys for fixed prosthesis. Electrochemical studies show that $\mathrm{Co}-\mathrm{Cr}$ alloys are more resistant to corrosion than Ni-Cr alloys. Nickel based alloys have a greater sensitization potential than cobalt-chromium alloys, whereas Co-Cr alloy allergies are rare. . $^{12,24}$

The clinical objective is to have the lowest marginal gap that still allows proper seating of the coping. All marginal fit values obtained for both the techniques in this study were within clinical permissible limits, that is, $120 \mu \mathrm{m}^{28}$. The marginal fit of 20 samples of DMLS technique varied between 24-33.5 $\mu \mathrm{m}$ as compared to conventional casting whose marginal fit varied from 34-54 $\mu \mathrm{m}$. This shows that consistent and better marginal fit values can be obtained with the DMLS technique. The comparison of overall mean marginal fit of copings made by DMLS technique was significantly superior to that of LW group ( $>0.001)$. This is inaccordance to the findings of Ortop et al, Huang et al. and $\mathrm{Xu}$ et al. ${ }^{21}$ who recorded lower discrepancies for laser sintered $\mathrm{Co}-\mathrm{Cr}$ than for cast $\mathrm{Co}$ Cr. ${ }^{11,18}$ Li et al observed 220 metal crowns for 24 months in order to evaluate the clinical effect of laser sintered
$\mathrm{Co}-\mathrm{Cr}$ and cast $\mathrm{Co}-\mathrm{Cr}$ metal crowns and found that laser sintered $\mathrm{Co}-\mathrm{Cr}$ metal crowns resulted in better marginal fit than cast $\mathrm{Co}-\mathrm{Cr}$ metal crowns. ${ }^{29}$

DMLS technique has its further advantages like less time in fabrication and a uniform thickness of metal coping. Reducing the technicians work in adjusting the coping to desired thickness and a uniform thickness of ceramic layer can be added.

DMLS is a relatively new method compared to conventional casting procedure. The ?t of CAD/CAM prosthetic frameworks may rely on the precision of the scanner that reads the abutments, on the ways in which the software can transform the scanning data into a $3 \mathrm{D}$ model on the computer, and on the accuracy of the machine that uses CAM to produce objects from the CAD data. ${ }^{8}$ The use of the DMLS technology may result in the most predictable fabrication method under the tested experimental conditions. However, clinical implementation of the DMLS system seems to require further investigation, because studies of restoration longevity are scarce.

\section{LIMITATIONS OF THE STUDY}

The tooth preparations for all the 40 specimens were carried out manually to simulate the oral environment which may have incorporated operator errors, but the preparations closely simulated the clinical conditions.

\section{CONCLUSION}

Within the limitations of this in vitro investigation, the following conclusions were drawn:

1. Both the casting techniques exhibited different results, disaproving the null hypothesis.

2. Copings fabricated with DMLS technique had better mnarginal fit when compared to copings fabricated from conventional lost wax technique.

The reference drawn from this study strongly suggests use of DMLS technique in place of conventional lost wax technique to fabricate copings for FPD in routinue dental practice. 


\section{REFERENCES}

1) Petteno D, Schierano G, Bassi F, Bresciano ME, Carossa S. Comparison of marginal fit of 3 different metal-ceramic systems: an in vitro study. Int J Prosthodont 2000; 13:405-408.

2) Hunter AJ, Hunter AR. Gingival margins for crowns: a review and discussion. Part 2. Discrepancies and configurations. J Prosthet Dent 1990;64:636-42.

3) Kim KB, Kim WC, Kim HY, Kim JH. An evaluation of marginal fit of three-unit fixed dental prostheses fabricated by direct metal laser sintering system. Dent Mater 2013;29(7):e91-6.

4) Bindl A, Mormann WH. Marginal and internal fit of allceramic CAD/CAM crowncopings on chamfer preparations. J OralRehabil 2005;32:441-7.

5) Valderhaug J, Birkeland JM. Periodontal conditions in patients 5 years following insertion of fixed prostheses. Pocket depth and loss of attachment. J Oral Rehabil 1976;3: 237-43.

6) Valderhaug J, Heloe LA. Oral hygiene in a group of supervised patients with fixed prostheses. J Periodontol 1977;48:221-4.

7) Lang NP, Kiel RA, Anderhalden K. Clinical and microbiological effects of subgingival restorations with overhanging or clinically perfect margins. J Clin Periodontol 1983;10:563-78.

8) Ucar Y, Akova T, Akyil M, Brantley W. Internal fit evaluation of crowns prepared using a new dental crown fabrication technique: laser-sintered $\mathrm{Co}-\mathrm{Cr}$ crowns. J Prosthet Dent 2009;102:253-259.

9) Faucher RR, Nicholls JI. Distortion related to margin design in porcelainfused-to-metal restorations. J Prosthet Dent 1980;43:149-55.

10) Buchanan WT, Svare CW, Turner KA. The effect of repeated firings and strength on marginal distortion in two ceramometal systems. J Prosthet Dent 1981;45:502-6.

11) Huang Z,Lu Zhang, Zhu J, Zhang X. Clinical marginal and internal fit of metal ceramic crowns fabricated with a selective laser melting technology. J Prosthet Dent 2015;113:623-27.

12) Anusavice KJ. Phillips' science of dental materials. 11th ed. Phialdelphia:W.B. Saunders; 2003.p. 565, 584, 585.

13) Vandenbroucke B, Kruth JP. Selective laser melting of biocompatible metals for rapid manufacturing of medical parts. Rapid Prototyping J 2007; 13:196-203.
14) Wu L, Zhu H, Gai X, Wang Y. Evaluation of the mechanical properties and porcelain bond strength of cobalt-chromium dental alloy fabricated by selective laser melting. J Prosthet Dent 2014;111:51-5.

15) Yang X, Xiang N, Wei B. Effect of fluoride content on ion release from castand selective laser melting-processed $\mathrm{Co}-\mathrm{Cr}$ Mo alloys. J Prosthet Dent2014;112:1212-6.

16) Zeng L, Xiang N, Wei B. A comparison of corrosion resistance of cobaltchromium-molybdenum metal ceramic alloy fabricated with selectivelaser melting and traditional processing. J Prosthet Dent 2014;112:1217-24.

17) Quante K, Ludwig K, Kern M. Marginal and internal fit of metal-ceramic crowns fabricated with a new laser melting technology. Dent Mater 2008;24:1311-1315.

18) Ortorp OA, Jonsson D, Mouhsen A, Von Steyern PV. The fit of cobalt-chromium three-unit fixed dental prostheses fabricated with four different techniques: A comparative in vitro study. Dent Mater 2011;27:356-363.

19) Oyagüe RC, Sánchez-Turrión A, López-Lozano JF, SuárezGarcía MJ. Vertical discrepancy and microleakage of lasersintered and vacuum-castimplant-supported structures luted with different cement types. J Dent 2012;40(2):123-30.

20) Kim KB, Kim WC, Kim HY, Kim JH. Evaluation of the marginal and internal gap of metal-ceramic crown fabricated with a selective laser sintering technology: two- and threedimensional replica techniques. J Adv Prosthodont 2013; 5(2): 179-186.

21) $\mathrm{Xu} \mathrm{D}, \mathrm{XiangN}$,Wei B. The marginal fit of selective laser melting- fabricated metal crowns: an in vitro study. J Prosthet Dent 2014;112:1437-1440.

22) Shillingburg HT. Fundamentals of fixed prosthosthodontics. 4th ed. USA: Quintessence publishing; 2012.p.149-164.

23) Att W, Komine F, Gerds T, Strub JR. Marginal adaptation of three different zirconium dioxide three-unit fixed dental prostheses. J Prosthet Dent 2009;101:239-247.

24) Bhaskaran E, Azhagarasan NS, Miglani S, Gajapathi B.Comparative Evaluation of Marginal and Internal Gap of Co-Cr Copings Fabricated from Conventional Wax Pattern, 3D Printed Resin Pattern and DMLS Tech: An In Vitro Study. J Indian ProsthodontSoc 2013; 13(3): 189-195.

25) Akova T, Ucar Y, Tukay A, Balkaya MC, Brantley WA. Comparison of the bond strength of laser-sintered and cast 
base metal dental alloys to porcelain. Dent Mater 2008;24(10):1400-4.

26) Beschnidt SM, Strub JR. Evaluation of the marginal accuracy of different all-ceramic crown systems after simulation in the artificial mouth. J Oral Rehabil 1999;26(7):582-93.

27) Nawafleh NA, Mack F, Evans J, Mackay J, Hatamleh MM. Accuracy and reliability of methods to measure marginal adaptation of crowns and FDPs: a literature review. J Prosthodont 2013;22(5):419-28
28) McLean JW, von Fraunhofer JA. The estimation of cement film thickness by an in vivo technique. Br Dent J 1971;131:107-11.

29. Li JM, Wang WQ, Ma JY. Comparison of the clinical effects of selective laser melting deposition basal crowns and cobalt chromium alloy base crowns. Shanghai Kou Qiang Yi Xue 2014;23:350-3.

Source of Support: Nil, Conflict of Interest: None Declared 